\title{
The studies that launched a thousand snips
}

$\mathrm{M}$ edical researchers may hope their work will eventually give rise to large-scale, wellfunded health programs, but those dreams rarely come true. Though it can happen and indeed did happen to three sets of researchers who conducted clinical trials in Africa several years ago. Their research, which linked circumcision to lower rates of HIV transmission, drew support from high-profile luminaries, donations from well-heeled philanthropists and resulted in mass circumcision programs in several African countries. Opponents of circumcision, however, claim those much-praised trials aren't all they were cracked up to be.

"For the past 100 years, advocates for circumcision have been coming up with ideas of why to circumcise boys," says Dr. George Denniston, founder of Doctors Opposing Circumcision, based in Seattle, Washington. "There was cancer of the penis, and then it was cancer of the cervix for their partners, and on and on. Now they have HIV. But the HIV studies are extremely flawed."

The first trial, published in 2005 , was conducted on 3274 uncircumsized men in South Africa, and found that circumcision can reduce HIV transmission in heterosexual men by up to 61\% (PLoS Med 2: e298. doi: 10.1371/ journal.pmed.0020298). "The first and obvious consequence of this study is that MC [male circumcision] should be recognized as an important means to reduce the risk of males becoming infected by HIV," the study states. "As shown by our study, MC is useful and feasible even among sexually experi- enced men living in an area with high HIV prevalence."

The second clinical trial was conducted in Rakai, Uganda, on 4996 uncircumcised men and found a reduction in HIV transmission of about 50\% (Lancet 2007;369:657-66). A similar rate of risk reduction was reported in the third trial, conducted on 2784 men in Kisumu, Kenya (Lancet 2007; 369:643-56). "Where appropriate, voluntary, safe, and affordable circumcision services should be integrated with other HIV preventive interventions and provided as expeditiously as possible," the second study states.

These results have proven to be very influential. Former United States President Bill Clinton, for instance, has referred to this data often in support of mass circumcision campaigns in Africa.

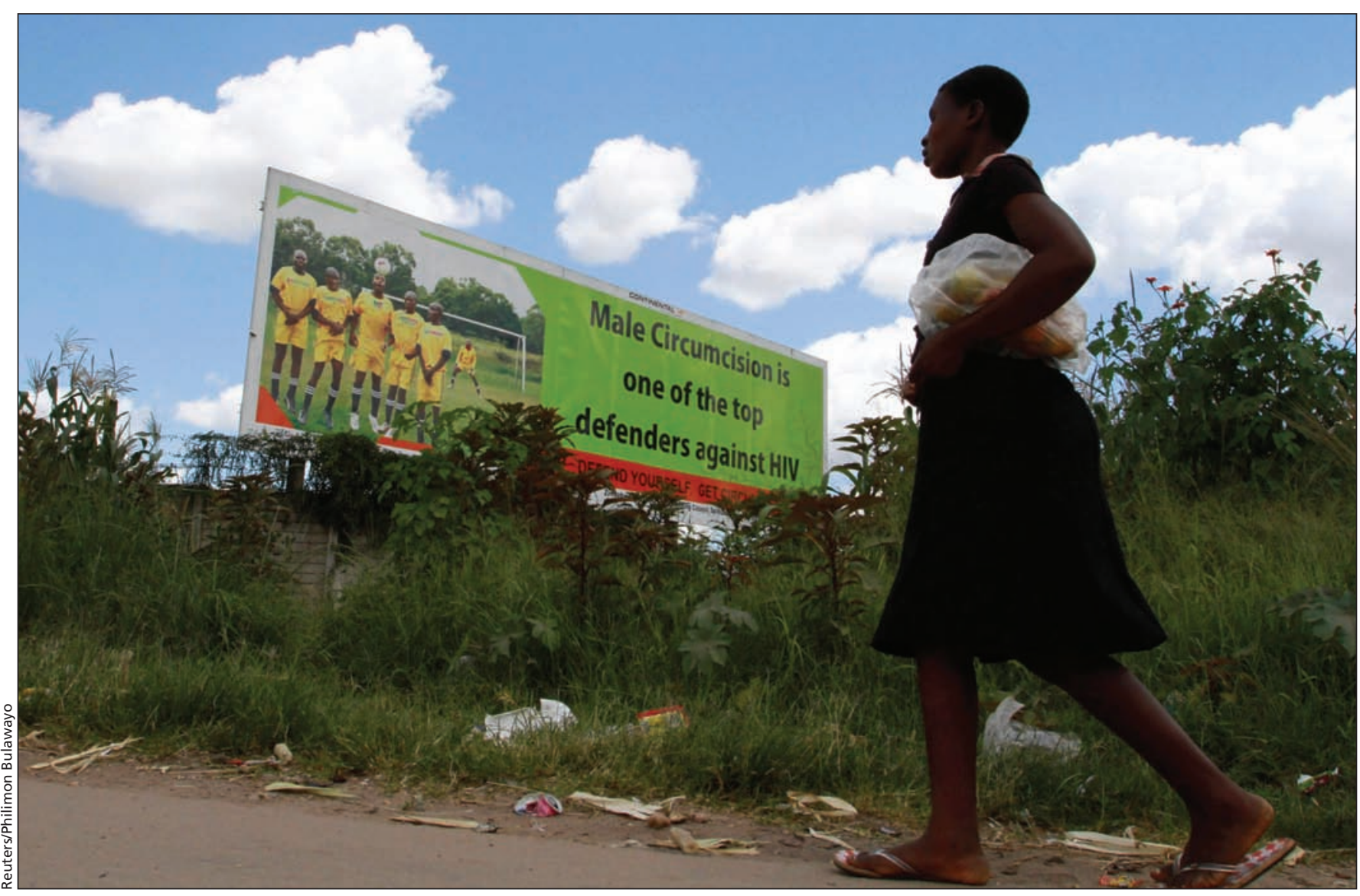

A woman walks past a billboard promoting male circumcision to combat HIV transmission in Harare, Zimbabwe. 
The trials also got the attention of the charity the Bill \& Melinda Gates Foundation, which gave US\$50 million in 2009 to fund a program to circumcise hundreds of thousands of men in Swaziland and Zambia. In his 2010 annual letter, Microsoft founder Bill Gates referred to a statistic - the $60 \%$ reduction in HIV transmission - that has become very popular in the pro-circumcision movement.

"I mentioned in last year's letter that studies have shown that male circumcision reduces the odds of transmission from a woman to a man by over 60 percent," the letter reads (www .gatesfoundation.org/annual-letter/2010 /Pages/hiv-aids-treatments-circumcision .aspx ?cmp=ALp7). "In areas where transmission is widespread, if you circumcise most of the men over 14 years old you can significantly reduce the spread of HIV."

Many people from the world of science and medicine also cite the research as being convincing, noting that it wasn't only one trial in one area. "The studies were triplicated, and they took place in three different parts of Africa," says Dr. Minh Dinh, assistant professor in medicine-infectious diseases at Northwestern University in Chicago, Illinois. "But there are questions some people still have. Would it apply in other groups in other parts of the world? Would it apply to men who have sex with men?"

Others note that the HIV trials are only further evidence of the potential health benefits of a procedure they see as being almost free of risk. "Since virtually all of the so-called 'risks' of circumcision are quite minor, and are immediately and easily treated and cured, whereas the long-term consequences of not circumcising include deaths from penile cancer, HIV/AIDs, etc. in men, and cervical cancer in the female partners ... the true benefits exceed the risks by an astronomical amount," Brian Morris, an advocate for circumcision and a professor of molecular medical sciences at the University of Sydney in Australia, writes in an email.

The research in support of circumcision, however, does not seem so impressive to Dr. John Travis, a member of the board of directors of the Alliance for Transforming the Lives of Children, a donation-supported educational organization based in Charlottesville, Virginia. "I can tell you that the research being touted as significantly protective of HIV is highly biased, poorly done," Travis writes in an email.

One the major problems, according to Travis, is that the researchers didn't determine the source of HIV infections acquired during the clinical trials, assuming all infections would be from heterosexual sex, though some of the infected men reported acquiring the virus during a period when they didn't have sex or had sex using condoms.

"Conservatively for the three trials, 89 of the 205 infections (43.1\%) were sexually transmitted," writes Travis. "Without knowing which infections were sexually transmitted, it is impossible to test the hypothesis of whether circumcision reduces the rates of sexually transmitted HIV."

Travis also claims the clinical trials were rife with various types of bias, such as attrition bias (the number of participants who dropped out vastly outnumbered those who became infected), duration bias (the trials were not long enough to determine if the positive effect would plateau) and expectation bias. Some of the primary investigators had already called for mass circumcision, Travis writes, so it is no surprise that they got the results they expected to see. This expectation of positive results may also explain why all three trials were terminated early.
Another form of bias in the research, writes Travis, is lead-time bias. The circumcised men were told not to have unprotected sex for 4-8 weeks, yet they were monitored immediately, as were the men in the uncircumcised group. The men in the control group were therefore exposed to infection for a longer period of time.

"It is like having a ten-mile race in which one group is give a 20-minute head start and then being surprised when the group with the head start finishes the race first," writes Travis.

There are also many social factors that bring the potential benefits cited in the research into question, according to John Geisheker, a lawyer and the executive director of Doctors Opposing Circumcision. When asked to elaborate, Geisheker directed CMAJ to a book chapter he had written on the topic (G.C. Denniston et al. Genital Autonomy. Springer Science+Business Media; 2010. p. 61-66).

In the chapter, Geisheker notes that mass circumcision could lead to problems in some settings. It could discourage the use of condoms, for example. Also, circumcised men are "likely to present themselves, especially to poor or illiterate village women, as rendered surgically immune to HIV."'

"The conundrum remains how FirstWorld circumcision proponents can remain so single-minded and intransigent while individual citizens of the target countries they claim to be 'saving' understand the village-level risks and costs," Geisheker wrote in the book. "We think this is simply a modern example of colonial medicine, complicated by a failure to learn from past failed efforts, such as vasectomy programs in India and an almost exclusive medical-model approach." - Roger Collier, CMAJ

CMAJ 2012. DOI:10.1503/cmaj.109-4029 